\title{
Constitutive Excitation by Gly90Asp Rhodopsin Rescues Rods from Degeneration Caused by Elevated Production of cGMP in the Dark
}

\author{
Michael L. Woodruff, ${ }^{1}$ Elena V. Olshevskaya, ${ }^{2}$ Andrey B. Savchenko, ${ }^{2}$ Igor V. Peshenko, ${ }^{2}$ Ronald Barrett, ${ }^{3}$ \\ Ronald A. Bush, ${ }^{4}$ Paul A. Sieving, ${ }^{4}$ Gordon L. Fain, ${ }^{1,5}$ and Alexander M. Dizhoor ${ }^{2}$ \\ ${ }^{1}$ Department of Physiological Science, University of California, Los Angeles, Los Angeles, California 90095, ${ }^{2}$ Hafter Research Laboratories, Pennsylvania \\ College of Optometry, Elkins Park, Pennsylvania 19027, ${ }^{3}$ Department of Anatomy and Cell Biology, Wayne State University, Detroit, Michigan 48202, \\ ${ }^{4}$ National Institutes of Health, National Eye Institute, National Institute on Deafness and Other Communication Disorders, Bethesda, Maryland 20892, and \\ ${ }^{5}$ Jules Stein Eye Institute, University of California, Los Angeles School of Medicine, Los Angeles, California 90095
}

Previous experiments indicate that congenital human retinal degeneration caused by genetic mutations that change the $\mathrm{Ca}^{2+}$ sensitivity of retinal guanylyl cyclase (retGC) can result from an increase in concentration of free intracellular cGMP and $\mathrm{Ca}^{2+}$ in the photoreceptors. To rescue degeneration in transgenic mouse models having either the Y99C or E155G mutations of the retGC modulator guanylyl cyclase-activating protein 1 (GCAP-1), which produce elevated cGMP synthesis in the dark, we used the G90D rhodopsin mutation, which produces constitutive stimulation of cGMP hydrolysis. The effects of the G90D transgene were evaluated by measuring retGC activity biochemically, by recording single rod and electroretinogram (ERG) responses, by intracellular free $\mathrm{Ca}^{2+}$ measurement, and by retinal morphological analysis. Although the G90D rhodopsin did not alter the abnormal $\mathrm{Ca}^{2+}$ sensitivity of retGC in the double-mutant animals, the intracellular free cGMP and $\mathrm{Ca}^{2+}$ concentrations returned close to normal levels, consistent with constitutive activation of the phosphodiesterase PDE6 cascade in darkness. G90D decreased the light sensitivity of rods but spared them from severe retinal degeneration in Y99C and E155G GCAP-1 mice. More than half of the photoreceptors remained alive, appeared morphologically normal, and produced electrical responses, at the time when their siblings lacking the G90D rhodopsin transgene lost the entire retinal outer nuclear layer and no longer responded to illumination. These experiments indicate that mutations that lead to increases in cGMP and $\mathrm{Ca}^{2+}$ can trigger photoreceptor degeneration but that constitutive activation of the transduction cascade in these animals can greatly enhance cell survival.

Key words: rod; retina; degeneration; cGMP; GCAP; guanylyl cyclase; calcium

\section{Introduction}

cGMP in photoreceptors is produced by the retinal guanylyl cyclase (retGC) modulated by guanylyl cyclase-activating proteins (GCAPs) (Palczewski et al., 2000; Dizhoor et al., 2006). $\mathrm{Ca}^{2+}$ inhibits rod retGC in the dark (Koutalos et al., 1995), when GCAPs are $\mathrm{Ca}^{2+}$ bound, but GCAPs stimulate retGC in the light, when $\mathrm{Mg}^{2+}$ replaces $\mathrm{Ca}^{2+}$ in the GCAPs (Peshenko and Dizhoor, 2004, 2006). The change in cGMP synthesis contributes to response recovery and adaptation to steady background light (Fain et al., 2001; Mendez et al., 2001; Burns et al., 2002).

\footnotetext{
Received Nov. 13, 2006; accepted June 26, 2007.

This work was supported by National Institutes of Health Grants EY11522 (A.M.D.), EY01844 (G.L.F.), EY04068 (Wayne State University Core, R.B.), and EY 00331 (Jules Stein Eye Institute, University of California, Los Angeles Core; M.L.W., G.L.F.), National Eye Institute/National Institute on Deafness and Other Communication Disorders intramural (P.A.S., R.A.B.), and Pennsylvania Lions Sight Preservation Foundation (A.M.D.). A.M.D. is the Martin and Florence Hafter Chair Professor of Pharmacology. We thank Xiaoging Liu, Clint Makino, and Tiansen Li (Massachusetts Eye and Ear Infirmary, Harvard Medical School, Boston, MA) for their help in studying morphological changes in L53 mice after prolonged illumination.

Correspondence should be addressed to Alexander M. Dizhoor, Hafter Research Laboratories, Pennsylvania College of Optometry, 8360 Old York Road, Elkins Park, PA 19027. E-mail: adizhoor@pco.edu.

D0I:10.1523/JNEUROSCI.2751-07.2007

Copyright $\odot 2007$ Society for Neuroscience $\quad$ 0270-6474/07/278805-11\$15.00/0
}

Multiple mutations in retGC1 and GCAPs can affect the $\mathrm{Ca}^{2+}$ sensitivity of cGMP synthesis and cause rod and cone degeneration (Kelsell et al., 1998; Payne et al., 1998; Tucker et al., 1999; Ramamurthy et al., 2001; Newbold et al., 2002; Nishiguchi et al., 2004; Sato et al., 2005; Sokal et al., 2005). One such mutation, Tyr99Cys (Y99C) in GCAP-1, shifts the $\mathrm{Ca}^{2+}$ sensitivity of the cyclase (Dizhoor et al., 1998; Sokal et al., 1998; Wilkie et al., 2000, 2001) and increases both cGMP and free $\mathrm{Ca}^{2+}$ in resting photoreceptors of transgenic mice that degenerate after the increase in $\mathrm{Ca}^{2+}$ concentration (Olshevskaya et al., 2004; Makino et al., 2006).

We reasoned that fast photoreceptor degeneration caused by enhanced production of cGMP in Y99C mice L53 (Olshevskaya et al., 2004) might be prevented by constitutive stimulation of cGMP phosphodiesterase PDE6, which degrades cGMP, closes channels and decreases $\mathrm{Ca}^{2+}$ (Pugh et al., 1997; Fain et al., 2001; Burns and Arshavsky, 2005). Because degeneration in Y99CL53 mice is detectable as early as after 3 weeks of age (Olshevskaya et al., 2004), the activation of PDE6 by the transduction cascade to counteract the effect of the Y99C GCAP-1 should be early and truly constant. We therefore mated mice expressing Y99C GCAP-1 with mice expressing the Gly90Asp (G90D) rhodopsin 
mutation, which has been shown to activate the phototransduction cascade constitutively in the absence of illumination (Rao et al., 1994; Jin et al., 2003) but without itself triggering significant degeneration (Sieving et al., 2001). In animals that express both the G90D and Y99C transgenes, the $\mathrm{Ca}^{2+}$ sensitivity of cGMP synthesis remained abnormal, but the outer segment (OS) current density and free $\mathrm{Ca}^{2+}$ both decreased, leading to preservation of photoreceptor structure and function. Partial preservation was also observed in the Y99C GCAP-1 mice in continuous bright ambient light.

Our experiments show that the rate of degeneration when cGMP and $\mathrm{Ca}^{2+}$ are aberrantly elevated by one pathway can be dramatically reduced by activation of an opposing mechanism that lowers cGMP and $\mathrm{Ca}^{2+}$. This provides compelling evidence that elevated levels of cGMP and $\mathrm{Ca}^{2+}$ that trigger apoptosis can be manipulated and rescued by activating opposing components of the phototransduction cascade.

\section{Materials and Methods}

Transgenic mice. All experimental procedures with the mice in this study were conducted in accordance with National Institutes of Health Guidelines, as approved by institutional animal investigation committees.

G90D rhodopsin/Y99C GCAP-1 mice. We used the transgenic mouse line L53, expressing the Y99C GCAP-1 mutant under control of the mouse opsin promoter as described by Olshevskaya et al. (2004). The mouse line transgenically expressing the G90D rhodopsin mutation in a rhodopsin knock-out background $\left(R^{-/-}\right)$has been characterized previously by Sieving et al. (2001). This line was rederived by embryonic transfer as the $G 90 D^{+/-} ; R^{-/-}$genotype and bred into the $G 90 D^{+/+}$; $R^{-/-}, G 90 D^{+/-} ; R^{-/-}$, or $R^{-/-}$genotypes. Suction electrode recordings and $\mathrm{Ca}^{2+}$ measurements were made from $G 90 D^{+/-} ; R^{+/-}$animals, which we designate in the rest of the paper as G90D. To produce a hybrid genotype, $Y 99 C^{+/-} ; G 90 D^{+/-} ; R^{+/-}$, we made the L53 line homozygous, that is as $Y 99 C^{+/+} ; R^{+/+}$, and bred these animals to $G 90 D^{+/-} ; R^{-/-}$mice to generate siblings in the same litters of genotypes $\mathrm{Y} 9 \mathrm{C}^{+/-} ; \mathrm{G} 90 \mathrm{D}^{+/-}$; $R^{+/-}$(designated in this paper as Y99C/G90D) and $\mathrm{Y}^{+} \mathrm{C}^{+/-} ; \mathrm{G}^{\circ} \mathrm{OD} \mathrm{D}^{-/-}$; $R^{+/-}$(designated in this paper as Y99C). In some cases, we bred the $Y 99 C^{+/+} ; R^{+/+} \mathrm{L} 53$ mice to either $G 90 D^{+/+} ; R^{-/-}$or $R^{-/-}$mice to pro-

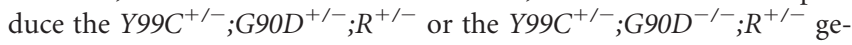
notypes, respectively. The presence of the transgenes coding for G90D and Y99C GCAP-1 were routinely confirmed by conventional tail DNA isolation using a Promega (Madison, WI) Wizard Genomic DNA kit according to the protocol of the manufacturer and PCR using pairs of primers: ACATGTTCCTGCTCATCGTGCTGG and GAGTGATGTGTAGAGGGTGGTG GTGAAGT; or AAAAAACCCATGGGGAACATTATGAGCGGTAAGTCGGTG and GGCGGTCATGGTCGAGTCGCTG, respectively.

G90D rhodopsin/E155G GCAP-1 mice. We expressed in mouse photoreceptors the E155G GCAP-1 mutant (designated in this paper as E155G) using the same methodology as described previously in detail for the Y99C GCAP-1 (Olshevskaya et al., 2004) by substituting the coding region in the transgenic construct for the Y99C GCAP-1 transgene with the coding region of the E155G GCAP-1 mutant. Two transgenic lines, L541 and L542, were originally produced by injecting fertilized mouse eggs of the B6/SVJ hybrid background at DNX/Xenogen (Cranbury, NJ); each was bred to the $\mathrm{B} 6$ mice for over 10 generations and tested for the lack of the $r d 1$ allele. Both lines developed rapid degeneration of the photoreceptors. The line L541 was subsequently used for producing the hybrids E155G ${ }^{+/-} ; G 90 D^{+/-} ; R^{+/-}$and $E 155 G^{+/-} ; G 90 D^{-/-} ; R^{+/-}$(designated as E155G/G90D and E155G in the rest of the paper), which were generated with the same schematics for breeding described above.

retGC activity. We collected dark-adapted mouse retinas aged 3-4 weeks in batches of four and freeze-thawed them using liquid nitrogen; they were then homogenized under infrared illumination on ice in a 1.5 $\mathrm{ml}$ test tube with a motor-driven plastic cone-shaped pestle in $250 \mu \mathrm{l}$ of $120 \mathrm{~mm} \mathrm{KCl,} 60 \mathrm{~mm}$ 3-( $\mathrm{N}$-morpholino)-propanesulfonic acid (MOPS),
pH 7.2, $10 \mathrm{~mm} \mathrm{NaCl}, 4.6 \mathrm{~mm} \mathrm{MgCl}_{2}, 0.2 \mathrm{~mm} \mathrm{ATP,} 50 \mu \mathrm{m}$ zaprinast, $50 \mu \mathrm{M}$ dipyridamole, $20 \mu \mathrm{g} / \mathrm{ml}$ leupeptin, and $20 \mu \mathrm{g} / \mathrm{ml}$ aprotinin. Each $20 \mu \mathrm{l}$ assay reaction, modified from Olshevskaya et al. (1997) and Hurley and Dizhoor (2000) as described by Peshenko and Dizhoor (2004) and Peshenko et al. (2004), contained $1 \mathrm{~mm}$ GTP, $1 \mu \mathrm{Ci}\left[\alpha^{-32} \mathrm{P}\right] \mathrm{GTP}, 0.1 \mu \mathrm{Ci}$ $\left[8-{ }^{3} \mathrm{H}\right]$ cGMP (PerkinElmer, Emeryville, CA), and 4 mM cGMP, 0.3 ATP, $2.5 \mathrm{~mm} \mathrm{MgCl}_{2}, 30 \mathrm{~mm}$ MOPS, pH 7.2, $5 \mathrm{~mm} \mathrm{NaCl}$, and $60 \mathrm{~mm} \mathrm{KCl}$, plus $25 \mu \mathrm{M}$ each of Zaprinast and dipyridamole, and $2 \mathrm{~mm} \mathrm{Ca}^{2+} /$ EGTA buffer prepared as described previously (Tsien and Pozzan, 1989; Marks and Maxfield, 1991; Brooks and Storey, 1992). We started the reaction by adding retinal homogenate and continued for $12 \mathrm{~min}$ at $30^{\circ} \mathrm{C}$ under infrared illumination. We stopped the reaction by heating at $95^{\circ} \mathrm{C}$ for 2 min and analyzed the products of the reaction by thin-layer chromatography on polyethyleneimine cellulose-coated fluorescent plates as described previously (Koch and Stryer, 1988; Hurley and Dizhoor, 2000).

Immunoblot and densitometry. Retinas collected in batches of four per $1.5 \mathrm{ml}$ standard Eppendorf plastic tube and homogenized in $200 \mu \mathrm{l}$ as described above were diluted fivefold in $5 \times$ standard Laemli's sample buffer for SDS electrophoresis. For comparison between wild-type (WT) and Y99C mice, the corresponding pairs of equal aliquots (with the exact volume in each pair of samples optimized for each of the antibodies used for the analysis) were separated in 15 or $7.5 \%$ SDS-polyacrylamide gel in $1 \mathrm{~mm}$ cassettes (Novex/Invitrogen, Wadsworth, $\mathrm{OH}$ ), transferred on Immobillon membrane, probed with primary antibodies, and developed with secondary horseradish peroxidase-conjugated antibody and chemiluminescent substrate (Femto SuperSignal; Pierce, Rockford, IL). The intensity of chemiluminescence in each case was quantified using CLXposure $\mathrm{x}$-ray film (Pierce), scanned by a Bio-Rad (Hercules, CA) GS4500 imaging densitometer. The proportionality of the signal on immunoblot was calibrated using series of dilutions of the wild-type retina sample loaded in the equivalent of 1 through $6 \mu \mathrm{l}$ per lane. The signal volume, measured in triplicates, increased with the amount of the sample between 2.4 and $19 \mathrm{OD} \mathrm{mm}^{2}$ in a quasi-linear manner (Fig. $1 c$, inset). The intensities of the signals for the antigens in Figure $1 b$ were adjusted by antibody dilution and the time of exposure to fit the signal volume between 2.5 and $13.8 \mathrm{OD} \mathrm{mm}{ }^{2}$. The antibodies against human retGC1 and retGC2 were produced using $\sim 20 \mathrm{kDa}$ recombinant protein fragments derived from the catalytic domain or kinase homology domain, respectively, both expressed from pET11d vector (Novagen/Calbiochem, La Jolla, CA) and purified from an Escherichia coli BLR(DE3) strain (Novagen/Calbiochem). The antibodies were raised in rabbits, and the IgG fraction of the serum was collected with ammonium sulfate precipitation. Antibodies against GCAP-1 and GCAP-2 (Olshevskaya et al., 2002) were produced in rabbits using full-size recombinant GCAPs purified from E. coli (Olshevskaya et al., 1997, 2004). Other primary antibodies were from Abcam (Cambridge, MA) (PDE6 $\alpha$, PDE6 $\beta$, and rhodopsin) or Santa Cruz Biotechnology (Santa Cruz, CA) (G $\alpha \mathrm{t} 1$ and G $\beta \mathrm{t} 1)$.

Suction-electrode recording. Methods for recording responses of mouse rods have been given previously (Woodruff et al., 2002, 2003). In brief, mice were dark adapted for at least $3 \mathrm{~h}$ and were killed and dissected under dim red light or in complete darkness under infrared illumination. The isolated retinas were chopped into small pieces with a razor blade and plated out onto a small Petri dish. Rods were perfused at $37^{\circ} \mathrm{C}$ with DMEM solution (D-2902; Sigma, St. Louis, MO) supplemented with 15 mм $\mathrm{NaHCO}_{3}, 2 \mathrm{~mm} \mathrm{Na}$ succinate, $5 \mathrm{~mm} \mathrm{Na}$ glutamate, $2 \mathrm{~mm} \mathrm{Na}$ gluconate, and $5 \mathrm{~mm} \mathrm{NaCl}$, and buffered with $5 \% \mathrm{CO}_{2} / 95 \% \mathrm{O}_{2}$ as described previously (Woodruff et al., 2002). Stimuli at $500 \mathrm{~nm}$ were attenuated with calibrated absorptive neutral-density filters. Light intensities were calibrated with a photodiode as described previously (Woodruff et al., 2002, 2003). Responses were amplified by a Warner Instruments (Hamden, CT) patch-clamp amplifier (PC 501A) or an Axopatch 200A (Molecular Devices, Palo Alto, CA) and recorded with pClamp hardware and software (Molecular Devices). They were low-pass filtered at $30 \mathrm{~Hz}$ with an eight-pole Bessel filter (Kemo, Beckenham, UK) and sampled by the digital-to-analog converter of pClamp at $100 \mathrm{~Hz}$. The single photon response was calculated from the squared mean and variance (Tsang et al., 2006). Data are given as means \pm SEs unless otherwise noted.

Calcium measurements. Calcium was measured as described previously (Woodruff et al., 2002). In brief, photoreceptors and retinal pieces 
a

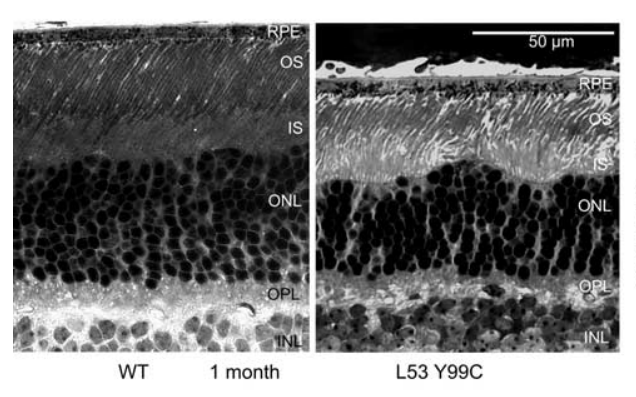

C

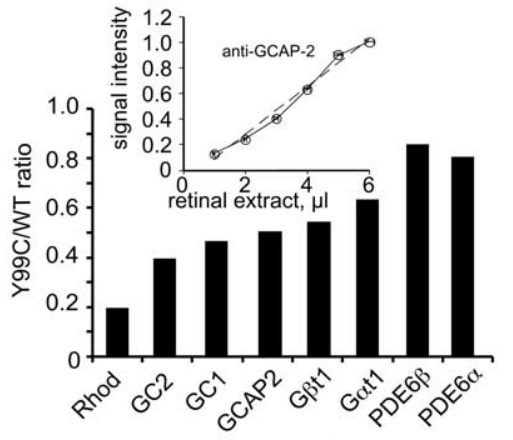

b

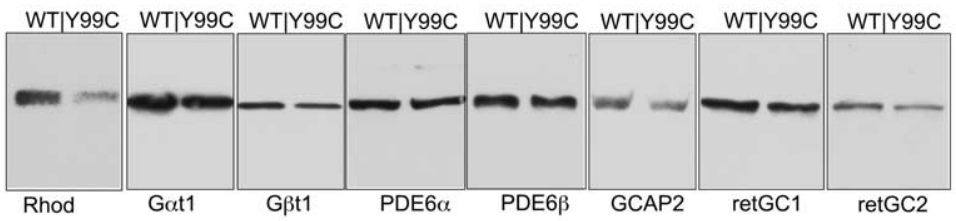

d
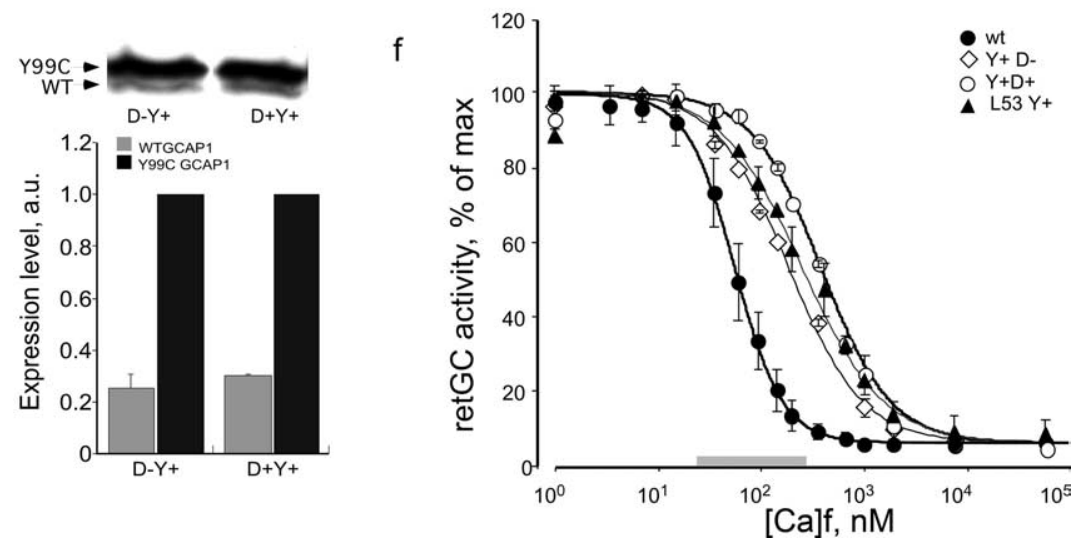

Figure 1. $\mathrm{Ca}^{2+}$ sensitivity of retGC remains abnormal in mice expressing both Y99C GCAP-1 and G90D rhodopsin. $\boldsymbol{a}$, Morphology of the retinas from wild-type and $\mathrm{Y} 99$ C mice at 1 month of age. rpe, Retinal pigment epithelium; os, outer segments; onl, outer nuclear layer; opl, outer plexiform layer; inl, inner nuclear layer. $\boldsymbol{b}$, Immunoblot from wild-type and $Y 99($ retinas at the age of 1 month probed with antibodies against rhodopsin (Rhod), $\alpha$ and $\beta$ subunits of transducin ( $\mathrm{G} \alpha \mathrm{t} 1$ and $\mathrm{G} \beta 1$ ), $\alpha$ and $\beta$ subunits of PDE6 (PDE6 $\alpha$ and PDE6 $\beta$ ), GCAP-2, and retGC isozymes (retGC1 and retGC2), averaged from two measurements. c, Content of the proteins in $\mathrm{Y} 99$ C retinas as shown in $\boldsymbol{b}$ evaluated by densitometry of immunoblot relative to the wild-type control. Inset, Relative signal intensity on immunoblot (solid line), calibrated using anti-GCAP-2 antibody as described in Materials and Methods; a would-be linear dependence is shown by the dashed line. $d$, Immunoblot of wild-type and Y99C GCAP-1 from L53 and a Y99C/ G90D mouse retinas aged 3.5 weeks separated in 15\% SDS-polyacrylamide gel and probed with anti-GCAP-1 antibody as described previously (Olshevskaya et al., 2004). $\boldsymbol{e}$, Ratio between WT and Y $99 \mathrm{C} \mathrm{GCAP-1} \mathrm{in} Y 99 \mathrm{C}^{+/-} ; R^{+/+}$and Y99C/G90D mice determined by densitometry of immunoblots, average of three independent measurements. The total amount of retinal material was adjusted to produce equal intensity signals on the blots for both strains. $f, \mathrm{Ca}^{2+}$ sensitivity of retGC in dark-adapted mouse retinas extracted from WT (black circles; $n=5$ ), L53 (black triangles; $n=2$ ), Y 99 C (white diamonds; $n=2$ ), and their Y 99 C/G90D littermates (white circles; $n=3$ ) at 3.5 weeks of age. The gray bar corresponds to the free $\mathrm{Ca}^{2+}$ change between light-adapted and dark-adapted states (Woodruff et al., 2002, 2003).

were exposed for $30 \mathrm{~min}$ at room temperature to $10 \mu \mathrm{M}$ fluo-5F-AM and then perfused at $37^{\circ} \mathrm{C}$ with bicarbonate-buffered DMEM as for suctionelectrode recordings. We illuminated rods with $488 \mathrm{~nm}$ laser light from an argon gas laser (American Laser Corporation, Salt Lake City, UT), focused as a $10 \mu \mathrm{m}$ diameter spot on the outer segment. To minimize dye bleaching, we attenuated the intensity of the laser to $2-5 \times 10^{10}$ photons $\mu \mathrm{m}^{-2} / \mathrm{s}$ with reflective neutral density filters. We detected emission with a low dark-count photomultiplier tube with a restricted photocathode (model 9130/100A; Electron Tubes, Rockaway, NJ), whose current was amplified by a low-noise current-to-voltage converter (PDA-700; Terahertz Technology, Oriskany, NY), filtered by a low-pass eight-pole Bessel filter at $1000 \mathrm{~Hz}$, and collected with pClamp at a sampling frequency of $2000 \mathrm{~Hz}$. We recorded the temperature of the perfusate within $0.5 \mathrm{~mm}$ of the rod with a miniature thermocouple and a digital thermometer to adjust the binding constant of the dye (Woodruff et al., 2002). We calibrated the intracellular concentration of $\mathrm{Ca}^{2+}$ in darkness and after illumination using the Michaelis-Menten equation $\left[\mathrm{Ca}^{2+}\right]=K_{\mathrm{D}}\left(F-F_{\min } / F_{\max }-F\right)$, where $K_{\mathrm{D}}$ is the temperature-adjusted dissociation constant of binding of $\mathrm{Ca}^{2+}$ to the dye, $F$ is the measured fluorescence at the beginning of the recording or at steady state in the presence of laser illumination, and $F_{\min }$ and $F_{\max }$ are the fluorescence minimum (in low $\mathrm{Ca}^{2+}$ ) and fluorescence maximum (in high $\mathrm{Ca}^{2+}$ ). We determined $F_{\min }$ by exposing the rod first to zero$\mathrm{Ca}^{2+}$ solution containing $10 \mu \mathrm{M}$ of the $\mathrm{Ca}^{2+}$ ionophore ionomycin, plus $140 \mathrm{~mm} \mathrm{NaCl}, 3.6$ $\mathrm{mm} \mathrm{KCl}, 3.08 \mathrm{~mm} \mathrm{MgCl}_{2}, 2.0 \mathrm{~mm}$ EGTA, and 3.0 mM HEPES, pH 7.4. We then determined $F_{\max }$ by exposing the rod to high $\mathrm{Ca}^{2+}$ solution $\left(50 \mathrm{~mm} \mathrm{CaCl}_{2}, 3.6 \mathrm{~mm} \mathrm{KCl}, 3.0 \mathrm{~mm}\right.$ HEPES, and 140 mm sucrose, $\mathrm{pH} 7.4$ ).

Histology and electron microscopy. Mice were killed by lethal injection of ketamine/xylazine and cervical dislocation; they were then perfused through the heart, first with Dulbecco's PBS and then with $1 \%$ glutaraldehyde in $0.1 \mathrm{M}$ sodium cacodylate buffer solution, $\mathrm{pH}$ 7.2. The eyes were removed and fixed for $12 \mathrm{~h}$ with $1 \%$ glutaraldehyde $/ 2 \%$ formaldehyde in $0.1 \mathrm{M}$ cacodylate buffer solution on ice. The fixative was removed, and the eyes were stored in $0.1 \mathrm{M}$ Sorensen's phosphate buffer for $48-72 \mathrm{~h}$ on ice, then placed in $0.8 \%$ glutaraldehyde $/ 2 \% \mathrm{OsO}_{4}$ in $0.1 \mathrm{M}$ Sorensen's phosphate buffer solution for $3 \mathrm{~h}$ on ice, washed briefly with PBS, then dehydrated using ethanol solutions and propyleneoxide, embedded in Embed resin (Electron Microscopy Sciences, Hatfield, PA) with the protocol of the manufacturer, cut into $1-\mu \mathrm{m}$-thick sections, and stained with a methylene blue/azure mixture for bright-field microscopy. Photographs were taken with an Olympus Optical (Tokyo, Japan) BX51 microscope/Magnafire digital imaging system. For electron microscopy, sections $\sim 90 \mathrm{~nm}$ thick were taken from the plastic-embedded retina specimens using Reichert Ultracut S (Mager Scientific, Dexter, MI) and photographed using a Jeol (Tokyo, Japan) 1010 TEM instrument with a Gatan (Pleasanton, CA) digital camera at Wayne State University Vision Core facility. In some cases, negative contrast was enhanced with uranyl acetate. Sections from some of the L53 mouse retinas reared under constant ambient light were provided by the courtesy of Dr. Tiansen Li (Dow Laboratories, Massachusetts Eye and Ear Infirmary, Boston, MA).

Electroretinography. We followed the ERG protocol of Lyubarsky et al. (2002), using a CWE BMA-200 bioamplifier (CWE, Ardmore, PA) and a Textronix (Wilsonville, OR) $220520-\mathrm{MHz}$ oscilloscope. The signal output was recorded with Axotape 2 software. Mice were dark adapted for $8-12 \mathrm{~h}$ and then sedated under dim red light $(20$ $\mathrm{mg} / \mathrm{kg}$ ketamine and $8 \mathrm{mg} / \mathrm{kg}$ xylazine). Phenylephrine (1\%) and tropicamide $(0.5 \%)$ eye drops were applied to the corneas to completely dilate the pupils, and the mice were dark adapted again for at least $10 \mathrm{~min}$ before the ERG recording. During the whole procedure, the mice were maintained at $37^{\circ} \mathrm{C}$ on a heated plate. The corneal electrode was a platinum wire in a small concave transparent plastic holder filled with a drop of water. A $1 \mathrm{~ms}$ flash adjusted by $510-520 \mathrm{~nm}$ interference filters and neutral density filters was delivered through the window of an aluminum ERG recording chamber coated with WRC-680 diffuse white reflectance coating (Labsphere, New Sutton, NJ). Light intensities ranged from 1.22 to 11,200 photons $\mu \mathrm{m}^{-2}$ at the cornea. An unfiltered saturating white flash exceeding $2.9 \times 10^{6}$ photons 
Table 1. Kinetic and sensitivity parameters of WT, $\mathrm{YgOC}^{+/-}, \mathrm{GgOD}^{+/-}$, and $\mathrm{Y99 \textrm {C } ^ { + / - }} ; \mathrm{GSOD}^{+/-}$rods $^{a}$

\begin{tabular}{|c|c|c|c|c|c|c|}
\hline & Dark current (pA) & $\begin{array}{l}\text { Time-to-peak } \\
(\mathrm{ms})^{b}\end{array}$ & Integration time (ms) & $\begin{array}{l}\tau \text { for response recov- } \\
\text { ery }(\mathrm{ms})^{c}\end{array}$ & $\begin{array}{l}\text { Flash sensitivity } \\
\left(\mathrm{pA} / \text { photon } \mu \mathrm{m}^{-2} \text { ) }\right.\end{array}$ & $\begin{array}{l}\text { Flash intensity at half-saturation } \\
\text { (photon } \mu m^{-2} \text { ) }\end{array}$ \\
\hline Wild-type & $11.9 \pm 0.5$ & $145 \pm 4(46)$ & $205 \pm 22(43)$ & $212 \pm 20(41)$ & $0.266 \pm 0.018(42)$ & $31 \pm 2(43)$ \\
\hline $199 \mathrm{C}^{+1-}$ & $8.8 \pm 0.7$ (19) & $178 \pm 9(19)$ & $142 \pm 11(20)$ & $115 \pm 20(19)$ & $0.165 \pm 0.028(20)$ & $43 \pm 11(19)$ \\
\hline $690 D^{+/-}$ & $6.5 \pm 0.5(34)$ & $110 \pm 5(29)$ & $110 \pm 11(28)$ & $94 \pm 6(33)$ & $0.027 \pm 0.002(36)$ & $179 \pm 15(32)$ \\
\hline $\mathrm{Yg9C}^{+/-} ; G 90 \mathrm{D}^{+/-}$ & $10.0 \pm 0.9(21)$ & $152 \pm 12(21)$ & $233 \pm 19(21)$ & $114 \pm 10(21)$ & $0.044 \pm 0.004(21)$ & $138 \pm 14(21)$ \\
\hline
\end{tabular}

${ }^{a}$ Values are means \pm SE with the number of cells in parentheses.

${ }^{b}$ Values are for dim light responses ( 15.5 photons $\mu \mathrm{m}^{2}$ ).

'Single-exponential fit of just saturating responses. Values in bold are significantly different from wild type $(p<0.01)$

$\mu \mathrm{m}^{-2}$ at the cornea was used to evoke the maximal a-wave amplitude with at least 3 min intervals between flashes.

\section{Results}

$\mathrm{Ca}^{2+}$ sensitivity of retGC in Y99C GCAP-1 mice with G90D rhodopsin remains abnormal

The Y99C mice derived from the parental line L53 (Olshevskaya et al., 2004) demonstrate the same rapid degeneration as the original L53 mice, and the first morphological change, shortening of the outer segments, can be clearly observed at 1 month of age (Fig. 1a). It was accompanied by a decrease of phototransduction proteins used as marker for outer segment proteins (Fig. 1b,c). The decreases in the content of transducin, isozymes of retGC, and GCAP-2 were consistent with the approximately twofold decrease in size of the outer segments in Y99C mice compared with wild type. The PDE was decreased to lesser extent, indicating perhaps a slight upregulation of the enzyme in response to the elevated level of cGMP. The small increase in PDE6 content, however, did not prevent the increase in CGMP and $\mathrm{Ca}^{2+}$ in the OS of the Y99C mice, as observed previously in L53 mice (Olshevskaya et al., 2004) and as described in detail later in this paper (see Figs. 2-4, Table 1). The content of rhodopsin was evidently decreased (Fig. 1b,c), consistent with the hemizygous rhodopsin genotype (Sieving et al., 2001) of the mice used in this study. It is important to emphasize that the hemizygous rhodopsin genotype does not by itself produce severe retinal degeneration, such as caused by the Y99C GCAP-1 transgene in L53 (Humphries et al., 1997; Sieving et al., 2001; Olshevskaya et al., 2004), and that ERG responses from hemizygous mice were virtually indistinguishable from those of wild-type mice at 6 months of age (data not shown).

Because the expression of G90D rhodopsin and Y99C GCAP-1 in their respective transgenic models were controlled by the same transcriptional signals (Sieving et al., 2001; Olshevskaya et al. 2004), the expression of G90D could potentially affect the level of expression of Y99C GCAP-1 in mice bred with the combined genotype and thus change the $\mathrm{Ca}^{2+}$ sensitivity of retGC in the Y99C mice. We therefore tested both the levels of expression for Y99C and the $\mathrm{Ca}^{2+}$ sensitivity of retGC in retinas of Y99C mice derived from the line L53 (Olshevskaya et al., 2004), in the absence and presence of the G90D rhodopsin transgene (Sieving et al., 2001). As we reported previously for the parental line L53 (Olshevskaya et al., 2004), the Y99C GCAP-1 (Fig. 1d, the top band on immunoblot) continued to be expressed in excess over the WT GCAP-1 (bottom band) in both Y99C and Y99C/G90D littermates (Fig. 1d,e). The rapid onset of rod cell death caused by transgenic expression of the Y99C GCAP-1 reduced the overall level of measurable activity of retGC to $60-70 \%$ of the WT level at 1 month of age, and the normalized $\mathrm{Ca}^{2+}$ sensitivity of the cyclase remained shifted nearly fivefold toward higher free $\mathrm{Ca}^{2+}$ concentrations compared with WT. This was also true in Y99C mice

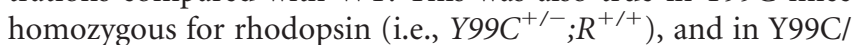

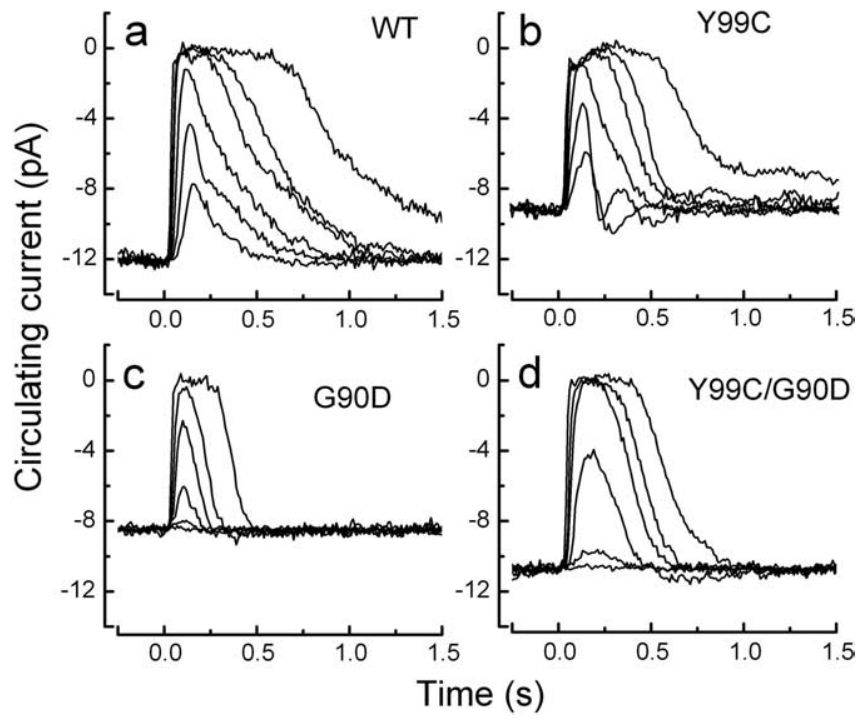

Figure 2. Suction-electrode current responses of representative WT and mutant mouse rods. Responses are to 20 ms flashes of $500 \mathrm{~nm}$ light delivering 17, 43, 160,450, 1100, and 4200 photons $\mu \mathrm{m}^{-2}$. Each trace was averaged from 5-20 flashes at lower intensities and 3-5 flashes at higher intensities. $\boldsymbol{a}$, WT; $\boldsymbol{b}$, Y99C; $\boldsymbol{c}$, G90D; $\boldsymbol{d}$, Y99C/G90D.

G90D mice produced by the breeding of $Y 99 \mathrm{C}^{+/+} ; R^{+/+}$and $G 90 D^{+/-} ; R^{-/-}$animals (Fig. $1 f$ ). In Y99C/G90D littermates, the total activity of the cyclase was greater than in Y99C mice and approximately the same as in the WT, but the $\mathrm{Ca}^{2+}$ sensitivity of Y99C/G90D retGC, normalized to its maximal activity, remained abnormal. Hence, the activity of retGC in Y99C and Y99C/G90D photoreceptors in the dark remained at an elevated level regardless of the presence or absence of the G90D rhodopsin transgene.

\section{Expression of G90D photopigment in Y99C rods alters rod} responses and outer segment $\mathrm{Ca}^{2+}$

G90D photopigment changes amplitude and sensitivity of Y99C rods but has little effect on response waveform

G90D rhodopsin has been shown to result in constitutive activation of the transduction cascade much as in the presence of continuous background light, in both humans (Sieving et al., 1995) and transgenic mice (Sieving et al., 2001). To examine the effects of introducing G90D into mice with the Y99C GCAP mutation, we first characterized the electrical responses of rods from animals with each of the single mutations and from the doublemutant Y99C/G90D animals.

Figure 2 shows typical responses from WT rods and the three types of rods we studied. Y99C rods (Fig. $2 b$ ) gave responses that differed noticeably from WT (Fig. $2 a$ ). The peak amplitude was smaller, responses at dim intensities showed oscillations and an overshoot, and saturating responses had a prominent component of slow decline, suggesting a larger than normal $\mathrm{Na}^{+} / \mathrm{K}^{+}-\mathrm{Ca}^{2+}$ 


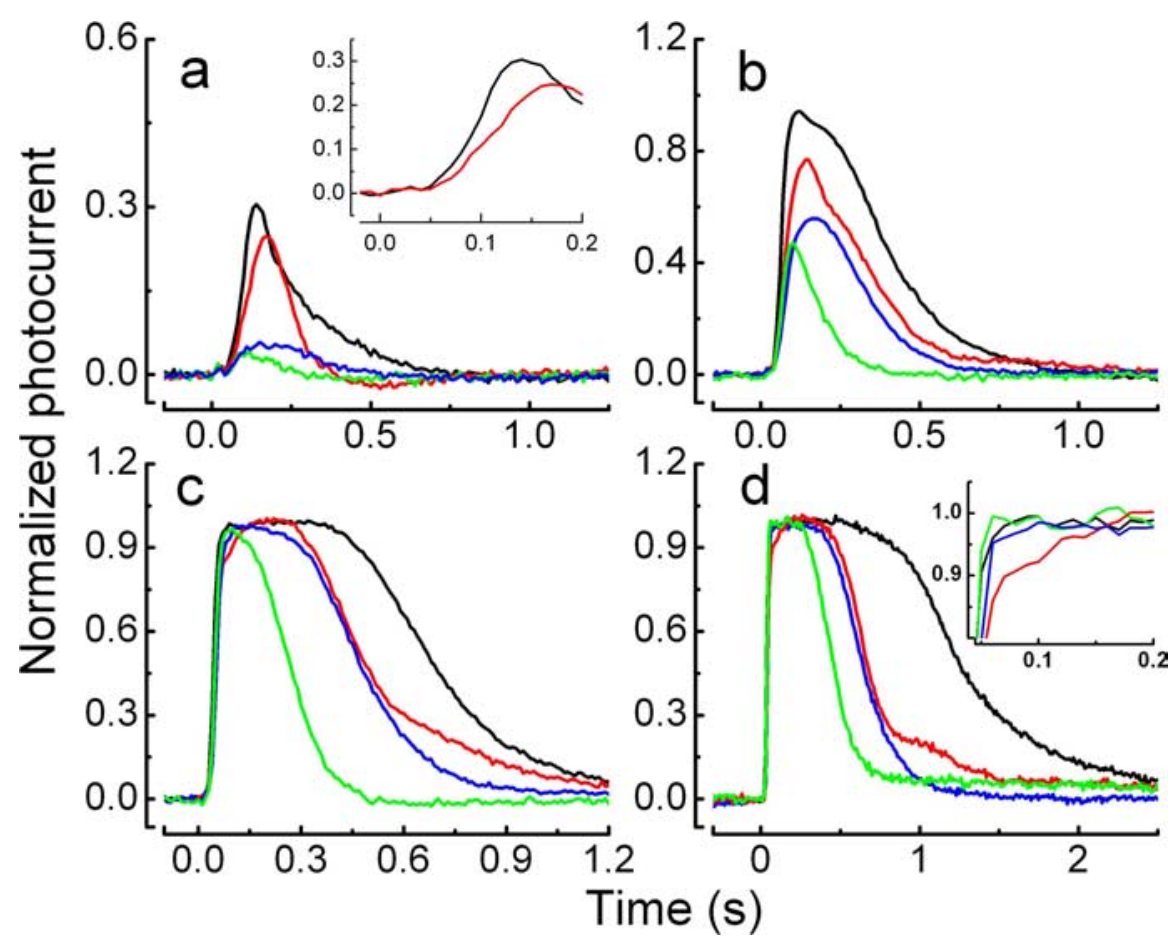

Figure 3. Mean normalized photocurrents from suction-electrode measurements superimposed to show differences in kinetics and response amplitude for WT (black traces; $n=35$ ), Y99C (red traces; $n=20$ ), G90D (green traces; $n=18$ ), and Y99 C/G90D (blue traces; $n=21$ ). The responses of each rod were normalized to the dark circulating current for that rod, and all the normalized responses at a given intensity from the different rods were averaged to calculate the plotted responses. The flash intensities were as follows: $\boldsymbol{a}, 17$ photons $\mu \mathrm{m}^{-2} ; \boldsymbol{b}, 160$ photons $\mu \mathrm{m}^{-2} ; \boldsymbol{c}, 1100$ photons $\mu \mathrm{m}^{-2}$; and $\boldsymbol{d}, 4200$ photons $\mu \mathrm{m}^{-2}$. $\boldsymbol{a}_{,}$Inset, the traces in $\boldsymbol{d}$ to show slow component of rise for the $Y 99 \mathrm{C} \mathrm{rods}$, caused by larger than normal $\mathrm{Na}^{+} / \mathrm{K}^{+}-\mathrm{Ca}^{2+}$ exchange current. Expansion of first $200 \mathrm{~ms}$ of the WT and Y99C traces in $\boldsymbol{a}$ to show difference in rise time. $\boldsymbol{d}$, Inset, Expansion of the first $200 \mathrm{~ms}$ of

expression. The decay of the Y99C response was consistently more rapid than WT, perhaps as a result of overstimulation of the cyclase in the dark (Fig. 1).

The averaged Y99C response appeared to rise at a slower initial rate than for WT. This is easiest to see in Figure $3 a$, from which we took the initial time course of the responses and calculated amplification constants according to Equation 23 of Pugh and Lamb (1993). We obtained a mean value of 6.5 for a normal WT mouse rod, in reasonable agreement with other values for mammalian photoreceptors [Pugh and Lamb (1993), their Table 6], but an apparent value of 3.8 for the Y99C rods. Although this would seem to suggest that the Y99C mutation alters the amplification of the transduction cascade, a simpler explanation is that the mutant rods are shorter and absorb fewer photons at any given light intensity. We therefore measured mean outer segment lengths in retinal sections and obtained mean values of $22 \pm 3 \mu \mathrm{m}$ (mean $\pm \mathrm{SD}$ ) for WT but only $10 \pm 3 \mu \mathrm{m}$ (mean $\pm \mathrm{SD}$ ) for Y99C rods at the age of the recordings. When the Y99C amplification factor is corrected for this difference, it becomes 8.4, even larger than WT perhaps as a result of the hemizygous expression of rhodopsin in the Y99C animals (Calvert et al., 2001).

The G90D responses (green traces) exchange current (Yau and Nakatani, 1984; Hodgkin et al., 1987). The smaller peak amplitude was probably mostly attributable to a shorter than normal outer segment length, as we describe in detail below. The oscillations are probably the result of the shift in $\mathrm{Ca}^{2+}$ sensitivity of the cyclase and hence the increase in cyclase activity; they were seen previously in recordings from L53 Y99C rods (i.e., $Y 99 C^{+/-} ; R^{+/+}$) (Makino et al., 2006), although they are larger and more consistently observed in our recent recordings from the $Y 99 \mathrm{C}^{+/-} ; \mathrm{R}^{+/-}$rods.

Responses from G90D rods (Fig. $2 c$ ) show many of the features expected from light-adapted cells. The circulating current in darkness was smaller than for WT rods, and responses decayed more rapidly, much as in the presence of continuous background light (Mendez et al., 2001; Makino et al., 2004; Fan et al., 2005). When, however, the G90D animals were mated with the Y99C heterozygotes to produce double-mutant animals, the dark current increased, although sensitivity remained depressed (Fig. 2d). The waveforms of the responses in the hybrid Y99C/G90D mice were mostly similar to those of the Y99C rods, with small oscillations again sometimes visible although never at the brightest flash intensities.

Changes in waveform can be more easily seen in Figure 3, in which we collected averaged responses of a large number of rods at four different light intensities. At the dimmest (17 photons $\mu \mathrm{m}^{-2}$ or $\sim 8 \mathrm{Rh}^{\star}$ per flash), the Y99C rod responses (red traces) were smaller than WT (black traces) and showed a small undershoot. Oscillations were less prominent in the averaged responses than in some of the recordings from individual rods, because the frequency of the oscillation was variable from cell to cell, likely attributable to individual variations in the levels of transgene were consistently smaller than WT as the result of the reduction in sensitivity produced by constitutive activation of the transduction cascade by the mutant rhodopsin (Sieving et al., 2001). The time course of response decay was also consistently accelerated. In the Y99C/G90D rods (blue traces), the sensitivity of the response was similar to G90D (Fig. 3a), but the wave forms (and in particular the time course of response decay) more closely resembled those of Y99C rods.

In the inset to Figure $3 d$, we show at a higher resolution the approach to saturation of the four responses in this panel. The Y99C response shows a slow component of the current decay already noted in Figure $2 b$, indicating a larger than normal $\mathrm{Na}^{+} /$ $\mathrm{K}^{+}-\mathrm{Ca}^{2+}$ exchange current. This appears consistent with the larger than normal free- $\mathrm{Ca}^{2+}$ concentration in the outer segments of these rods (Olshevskaya et al., 2004). The rods from the other animals did not show a similar slow decay, consistent with their outer segment $\mathrm{Ca}^{2+}$ concentration not being elevated to the level of the Y99C mice (see below).

In Table 1, we collected several parameters of interest for the four rod types. Means that are significantly different from WT (Student's $t$ test, $p<0.01$ ) are indicated in bold. Of interest are the lower sensitivities of both the G90D and Y99C/G90D rods and the accelerated decay (increased $\tau$ for response recovery) for all three types of mutant receptors.

\section{Single-photon responses}

In Figure $4 a$, we compare the single-photon responses of the four kinds of rods, calculated from the mean and variance of responses to dim intensities as described previously (Tsang et al., 2006). The WT and Y99C now show no significant difference in rise time, as 

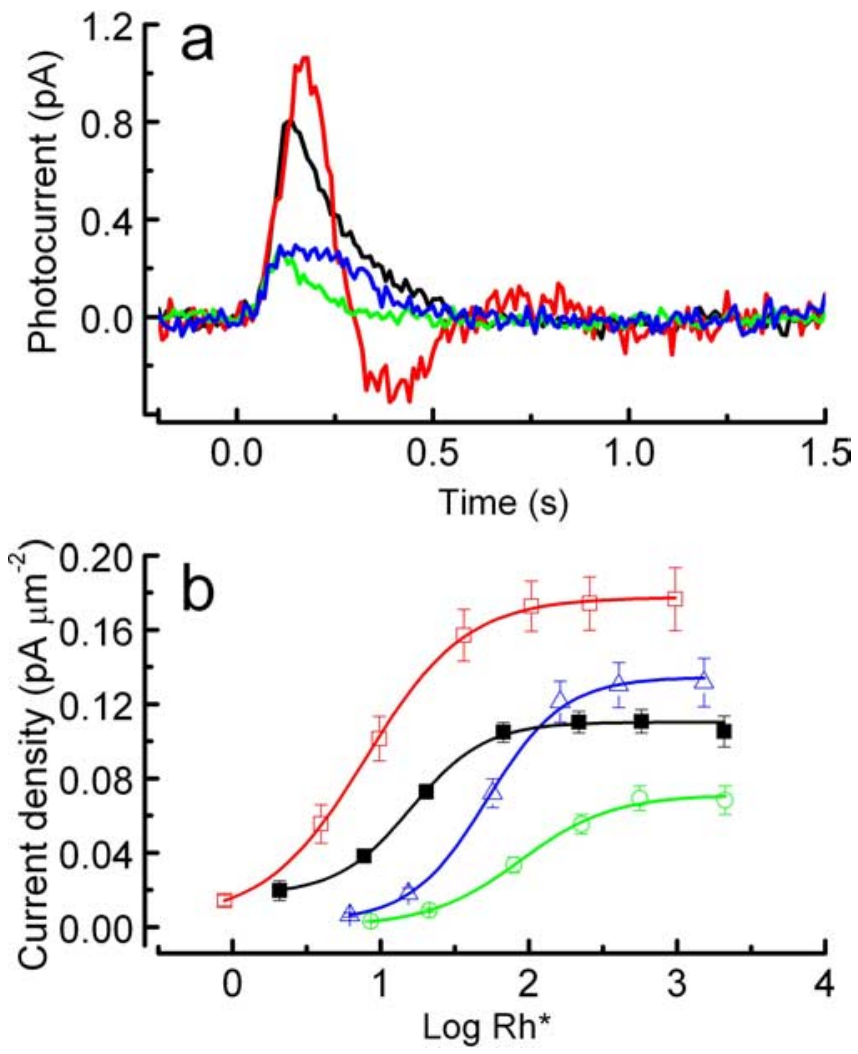

Figure 4. Single-photon responses and intensity-response relationships of WT and mutant rods. $\boldsymbol{a}$, Single-photon responses for WT (black), Y99C (red), G90D (green), and Y99C/G90D (blue). Responses were calculated from suction-electrode measurements of small-amplitude responses ( $<20 \%$ of maximum response) from the squared mean and variance (Tsang et al., 2006) and were averaged from 14 (WT), 20 (Y99C), 16 (G90D), and 18 (Y99C/G90D) rods. $\boldsymbol{b}$, Mean intensity-response functions for WT (black), Y99C (red), G90D (green), and Y99C/G90D (blue) averaged, respectively, from 32, 19, 10, and 21 cells. Response amplitudes and flash intensities were adjusted to compensate for different lengths of outer segments as described in Results. The data have been fitted with Boltzmann exponential functions.

would be expected because the light intensities are effectively the same despite the difference in outer segment length. The amplitude of the Y99C response is however significantly larger (WT, $0.82 \pm 0.07, n=15 ;$ Y99C, $1.21 \pm 0.12, n=19 ; p<0.02)$. The amplitudes of the other responses are significantly smaller than WT (G90D, $0.25 \pm 0.03, n=15$; Y99C/G90D, $0.34 \pm 0.03, n=$ $16 ; p<0.1$ ), consistent with desensitization of the photoreceptor produced by constitutive activation of the PDE cascade by the G90D mutation as in background light. The differences in wave form are consistent with those in Figure 2 and Table 1.

\section{Response-intensity curves corrected for outer segment area}

Although single-photon responses provide a useful comparison when outer segment lengths are different, we sought another way of doing this over the entire intensity range. Accordingly, we plotted response-intensity functions as current densities, correcting for the differences in outer segment length. Values of the lengths for WT and Y99C were given above. No correction was made for G90D rods, because the OS length was not significantly different from WT (Sieving et al., 2001), but Y99C/G90D rods were somewhat shorter with a mean outer segment length of $16 \pm$ $3 \mu \mathrm{m}$ (mean $\pm \mathrm{SD})$. Outer segment diameters for the rods of the four groups of animals were all $\sim 1.5 \mu \mathrm{m}$.

Diameters and lengths were used to calculate outer segment membrane area. Currents were then divided by area to give cur- rent densities in units of picoamperes per square micrometer. The intensities of the flashes were also corrected for the differences in collecting area and plotted as rhodopsins bleached per flash. We assumed a collecting area for a WT mouse rod of 0.5 $\mu \mathrm{m}^{2}$ (Field and Rieke, 2002) and used this value also for the G90D rods; for the other mice, the values we used were $0.23 \mu \mathrm{m}^{2}$ for Y99C and $0.36 \mu \mathrm{m}^{2}$ for Y99C/G90D.

The results of these calculations are given in Figure $4 b$. It is now apparent that Y99C rods have a greater circulating current density and sensitivity than WT rods, as would be expected from the higher activity of the cyclase in darkness. The free cGMP concentration inside the OS is greater, and a larger proportion of the cGMP-gated channels are open. The G90D mutation produced a large decrease in both sensitivity and circulating current density. In the double-mutant animals, there was little change in sensitivity but a significant increase in circulating current density, again as the result of the increase in free cGMP produced by the shift in the $\mathrm{Ca}^{2+}$ dependence of the cyclase. The effect of the Y99C mutation was remarkably similar for the WT and the G90D genetic backgrounds, once the response-intensity curves had been corrected for the difference in outer segment dimensions.

\section{$\mathrm{Ca}^{2+}$ measurements from single rods}

Measurements of $\mathrm{Ca}^{2+}$ were made from the outer segments of rods of the four types of mice with the fluorescent dye fluo-5F as described previously (Woodruff et al., 2002; Olshevskaya et al., 2004). Each rod was first exposed to the bright saturating light of the laser to measure the initial value of the fluorescence, which we took as resting value of $\mathrm{Ca}^{2+}$ in the outer segment in darkness. We took the steady-state value after light exposure as the value of the fluorescence with all the cGMP-gated channels closed. These were then calibrated in situ for each rod by individually exposing each outer segment to a zero- $\mathrm{Ca}^{2+}$ solution and a high-Ca ${ }^{2+}$ solution in the presence of the $\mathrm{Ca}^{2+}$ ionophore ionomycin (see Materials and Methods). This procedure corrects for any differences in dye loading among the rods or for possible differences in laser intensity from one experiment to another.

The results of these measurements were as follows. In darkness, the free- $\mathrm{Ca}^{2+}$ concentrations (mean $\pm \mathrm{SE}$ ) were $355 \pm 45$ $(n=10)$ forY99C, $291 \pm 28(n=11)$ for Y99C/G90D, $240 \pm 17$ $(n=56)$ for WT (collected from Woodruff et al., 2002, 2003; Olshevskaya et al., 2004), and $143 \pm 31(n=10)$ for G90D. These are in the ratio of 1.5:1.2:1.0:0.6 (for Y99C/Y99C/G90D/WT/ G90D). This is similar to the ratios of the dark circulating current densities, which from Figure $4 b$ after correction for the differences in outer segment length were 1.6:1.2:1.0:0.6. The free-Ca ${ }^{2+}$ concentrations in the light were similar for the four types of rods: $55 \pm 10$ for Y99C, $65 \pm 14$ for Y99C/G90D, $46 \pm 10$ for WT, and $51 \pm 15$ for G90D.

\section{Expression of G90D rhodopsin preserves structure of photoreceptors with Y99C GCAP-1 mutation}

As in our previous experiments with the L53 line of Y99C GCAP mice (Olshevskaya et al., 2004), most of the photoreceptors in the retinas of Y99C mice in this present study disappeared after 4 months of age. At 6 months of age, only a few photoreceptor nuclei could be identified per $100 \mu \mathrm{m}$ length of retinal section, with none of the outer segments usually present. The inner nuclear layer was nearly continuous with the retinal pigment epithelium (Fig. $5 a-c$ ). In contrast, the histological organization of the retina in Y99C/G90D siblings closely resembled that of the WT (Fig. $5 a$ ). Nearly $60 \%$ of the cells in the outer nuclear layer survived (Fig. 5b), and the remaining Y99C/G90D photorecep- 
a
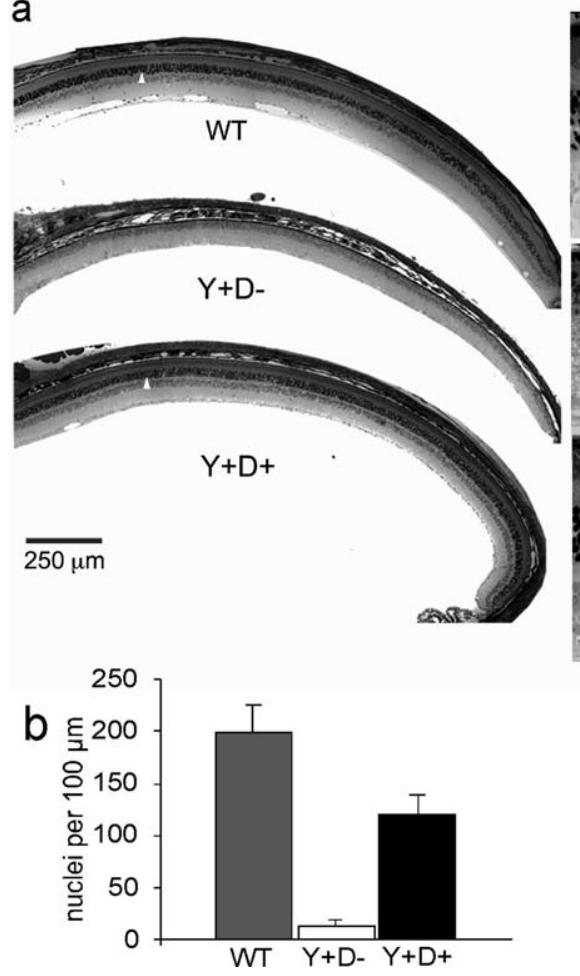

Figure 5. Rescue of rods from degeneration caused by Y99C GCAP-1. $\boldsymbol{a}$, Light microscopy of retinal sections from 5.5-monthold WT mice (top) and Y99C and Y99C/G90D (bottom) littermates at lower (10× objective, left) and higher (40X objective, right) magnification; notice the lack of the outer nuclear layer in $Y 99 \mathrm{C}$ mice and its reappearance in their $Y 99 \mathrm{C} / \mathrm{G} 90 \mathrm{D}$ siblings indicated by white arrows. rpe, Retinal pigment epithelium; 0s, outer segments; onl, outer nuclear layer; opl, outer plexiform layer; inl, inner nuclear layer; ipl, inner plexiform layer; $\mathrm{gl}$, ganglion cell layer. The left is reconstruction from several frames of the same retina sections at $10 \times$ objective. $\boldsymbol{b}$, Photoreceptor nuclei count (mean \pm SD) per $100 \mu \mathrm{m}$ in WT, Y99C, and Y99C/G90D littermates aged 4-6 months: $197 \pm 28, n=12 ; 14 \pm 6, n=10 ; 120 \pm 17, n=13$, respectively. $\boldsymbol{c}$, $\boldsymbol{d}$, Electron microphotograph (at magnification of $1200 \times)$ of the distal retina in $Y 99 C(\boldsymbol{c})$ versus $Y^{+} ; D^{+} ; R^{+/-}$littermate (d) at 5.5 months of age. Scale bar, 10 $\mu \mathrm{m}$. ros, Rod outer segment; cos, cone outer segment; ris, rod inner segment; cis, cone inner segment. Notice the lack of outer nuclear layer in cand the apparently normal morphology of rods in d. e, Photoreceptor disks in 5.5-month-old Y99C/G90D mouse rods (picture taken at magnification of $30,000 \times$ )

tors retained a normal appearance (Fig. $5 a, d$ ). Although the outer segments in the Y99C/G90D rods were $<80 \%$ their normal length, even in 6-month-old animals we did not observe distortion in disk stacking (Fig. 5e) as in parental Y99C L53 mice (Makino et al., 2006). The restoration of the photoreceptor layer in Y99C/G90D mice occurred along the whole extent of the retina rather than in distinct patches (Fig. $5 a$, bottom) compared with the complete lack of photoreceptors everywhere in the retinas of Y99C siblings (Fig. 5a, middle).

\section{Restoration of ERG responses in Y99C/G90D mice}

Y99C mice progressively lost their ERG response (Fig. $6 a, b$ ) in a manner similar to the parental L53 line (Olshevskaya et al., 2004); after 4 months of age, the b-wave was greatly reduced compared with WT mice, and the a-wave was barely detectable, even at very bright flash intensities (Fig. 6a,b). The Y99C/G90D siblings, conversely, all had clear a-wave and b-wave ERG responses (Fig. $6 a-d)$. Although the maximal a-wave of the Y99C/G90D retinas between 4 and 6 months $(227 \pm 76 \mu \mathrm{V}$, mean $\pm \mathrm{SD} ; n=58)$ was only half its normal amplitude $(430 \pm 78 \mu \mathrm{V}$, mean $\pm \mathrm{SD} ; n=$ 28 ), it was much larger than for Y99C littermates lacking the G90D transgene $(14.5 \pm 15 \mu \mathrm{V} ; n=27)$. The light sensitivity of the ERG in Y99C/G90D mice was suppressed by nearly 1 log unit compared with WT; at light intensities below 50 photons $\mu \mathrm{m}^{-2}$ at cornea (Fig. $6 a, d$ ), the cornea-positive b-wave was much smaller than in WT or undetectable, reflecting the decreased sensitivity of the photoreceptors in these animals (Figs. $3 a$, $4 b)$. However, at brighter intensities, nearly normal b-waves could be recorded (Fig. $6 c, d$ ). The ERG of Y99C/G90D mice closely resembled that recorded previously from G90D mice (Sieving et al., 2001), although Y99C GCAP-1 continued to be expressed in $\mathrm{Y} 99 \mathrm{C} / \mathrm{G} 90 \mathrm{D}$ retinas at this age to a greater extent than WT GCAP-1 (data not shown).

\section{Expression of G90D rhodopsin also preserves the structure of photoreceptors and restores the ERG of E155G GCAP-1 mice}

We created an additional transgenic model that expressed the E155G mutation of GCAP-1, also found in human patients with congenital retinal degeneration (Wilkie et al., 2001). We replaced the cDNA fragment coding for Y99C GCAP-1 with the E155G and introduced it under the control of a $4.2 \mathrm{~kb}$ opsin promoter by random insertion into mouse egg DNA as by Olshevskaya et al. (2004). We generated two transgenic mouse lines, L541 and L542, which both demonstrated a prominent shift in $\mathrm{Ca}^{2+}$ sensitivity of retGC (the L541 is shown in Fig. 7a) and developed rapid retinal degeneration such that 1-month-old mice already have fewer than $50 \%$ of the normal number of photoreceptor nuclei and severe distortion and shortening of outer segments (Fig. $7 b$, inset). By 3 months of age, all the photoreceptors had degenerated, in contrast to their transgene-negative siblings (Fig. 7b). However, when the E155G GCAP-1 transgene was placed into the $G 90 D^{+} ; R^{+/-}$genetic background, the E155G/Y99C mice retained $>50 \%$ of their photoreceptors at 3 months of age, unlike their E155G littermates, which had the same degeneration of the entire outer nuclear layer as in the parental L541 E155G $\mathrm{G}^{+} ; R^{+/+}$mouse line (Fig. 7c).

The E155G mice had no ERG response to illumination by 3 months of age (Fig. $7 d, e$ ). In contrast, their E155G/G90D littermates responded well with clearly visible a-waves (maximal a-wave amplitude of $194 \pm 3 \mu \mathrm{V}$, mean $\pm \mathrm{SD} ; n=10)$ and b-waves to light stimuli above 50 photons $\mu \mathrm{m}^{-2}$ (Fig. $7 d$ ). Like the Y99C/G90D mice, the E155G/G90D mice 3-4 months of age had a reduced sensitivity to light and a reduced $b$-wave amplitude to stimuli below 50 photons $\mu \mathrm{m}^{-2}$ (data not shown), whereas their E155G siblings at that age had a barely detectable a-wave $(3 \pm 5 \mu \mathrm{V}$, mean $\pm \mathrm{SD} ; n=13)$ and little or no b-wave (Fig. $7 d, e)$.

\section{Rearing L53 mouse rods in constant illumination can also partially rescue photoreceptors}

The dramatic difference between rapidly degenerating Y99C mice and their rescued Y99C/G90D littermates was observed when mice were reared under cyclic illumination (12 h light/ dark), of $\sim 2-10$ lux measured in different cages during the light cycle. Because PDE6 is normally activated by light, we also investigated the effect of rearing Y99C mice under constant illumina- 
tion in the L53 mouse line, the high expressor of Y99C GCAP-1 (Olshevskaya et al., 2004), which was used as the parental line for the Y99C/G90D and Y99C siblings. We exposed a group of five L53 mice to constant ambient light of $\sim 40-110$ lux measured in different parts of the cages, and another group of seven L53 mice to a constant incandescent light producing 200-700 lux in different parts of the cages. A control group of 10 L53 mice was kept under normal lighting conditions in a $12 \mathrm{~h}$ dark/light cycle. After 2.5 months of exposure, we recorded the ERG and compared retinal morphology in these three groups (Fig. $8 a-g$ ). The constant $40-110$ lux-exposed animals showed slight improvement in the averaged ERG compared with their cyclic light-reared littermates (Fig. $8 a$ ), but the maximum amplitude of the ERG remained smaller than in Y99C/ G90D mice of the same age $(p<0.05)$ (Fig. 8d) (supplemental Fig. 1, available at www.jneurosci.org as supplemental material), whose a-wave averaged $302 \pm 32 \mu \mathrm{V}$ (mean $\pm \mathrm{SE}$ ) and b-wave $640 \pm 84 \mu \mathrm{V}$. The ERG remained difficult to measure and was not identifiable in some animals (Fig. $8 b$ ). Prolonged light exposure was slightly beneficial for the preservation of the retinal morphology in the 40-110 lux group as well: at 3 months, four of five of the L53 mice had between two and three layers of photoreceptor nuclei, whereas none of their littermates kept in cyclic light had even one complete layer. The L53 mice that were constantly exposed to the light also had an identifiable layer of inner segments, unlike their littermates kept under regular cyclic light. Preservation was, however, much less than for Y99C/G90D mice, because nearly twothirds of photoreceptor nuclei were missing, and we were unable to identify outer segments (Fig. $8 f$ ).

The increase in intensity of the ambient illumination to 200 700 lux further improved both the ERG and the retinal morphology (Fig. $8 c, d, f$ ). The averaged a-wave became $55 \pm 21 \mu \mathrm{V}$ (mean $\pm \mathrm{SE} ; n=7$ ) compared with no a-wave in the control group, and the b-wave was also much higher (138 \pm 46 vs $7.7 \pm$ $5.3 \mu \mathrm{V} ; n=9 ; p<0.05)$. However, the magnitude of the rescue varied among the 200-700 lux-exposed animals: five of seven had a measurable ERG b-wave, and four had also an a-wave. In one animal, the a-wave reached half the normal amplitude, yet two of seven animals had neither a-wave nor b-wave (supplemental Fig. 1, available at www.jneurosci.org as supplemental material), despite the fact that all these littermates carried the same Y99C GCAP-1 transgene from the same L53 parent.

Morphological features of the retina in the light-exposed animals also further improved in the 200-700 lux group (Fig. 8g) (supplemental Fig. 2, available at www.jneurosci.org as supplemental material). In a representative sample shown in Figure $8 g$, not only photoreceptor inner segments but also shortened outer segments were clearly visible. The extent to which the structure of the retina was improved, much like the ERG amplitude, varied among animals and in different parts of the retina (supplemental Fig. 2, available at www.jneurosci.org as supplemental material),
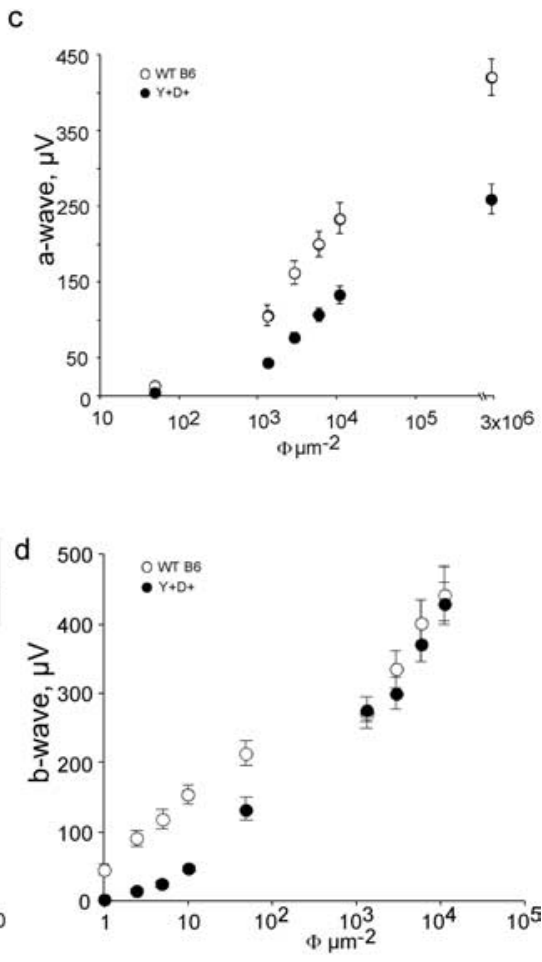

Figure 6. Restoration of dark-adapted ERG responses in Y99C GCAP-1 mice expressing G90D rhodopsin. $\boldsymbol{a}$, Typical ERG re作), Y99C (middle), and their Y99C/G90D littermates (right) after 5 months of age, flash strength increase circles; $n=16$ ) mice at $4-6$ months of age. $\boldsymbol{d}$, ERG b-wave sensitivity in WT (open black circles; mean \pm SE; $n=17$ ) and $\mathrm{Y99C/G90D} \mathrm{(filled} \mathrm{blue} \mathrm{circles;} n=16$ ) mice at $4-6$ months of age. Notice the strong reduction in sensitivity to dim flashes.

but degeneration was nevertheless reduced compared with the cyclic lighting group.

\section{Discussion}

To slow the rate of degeneration in Y99C animals, we attempted to decrease free cGMP by constitutively activating cGMP phosphodiesterase, in the hope that the reduction in the opening of the cGMP-gated channels would be sufficient to lower the abnormally high free- $\mathrm{Ca}^{2+}$ concentration produced by the Y99C mutation. To do this, we mated Y99C mice with a mouse line carrying the G90D mutation of rhodopsin. Rod responses in G90D mice have a decreased sensitivity (Figs. $2 c, 4 b$ ) and an accelerated decay (Fig. 3, green traces), much like receptors exposed to background light, consistent with other data showing that the G90D mutation produces constitutive activation of the transduction cascade (Sieving et al., 2001). Mice carrying both the GCAP-1 Y99C and the rhodopsin G90D mutations continue to show decreased $\mathrm{Ca}^{2+}$ sensitivity of retGC as in Y99C rods (Fig. 1c) and a decreased sensitivity as in mice with G90D alone (Figs. 3a, 4a,b), but the current density and outer segment $\mathrm{Ca}^{2+}$ in the Y99C/G90 mice are both brought much closer to their normal WT levels (Fig. 4c). Furthermore, retinal degeneration is slower and far less severe than in Y99C mice. Some preservation of structure and function was also achieved by exposing Y99C mice to continuous bright illumination.

We assumed that the peak photocurrent density is equivalent to the circulating current density of the rod in darkness (Baylor et al., 1979), which in turn reflects the free concentration of cGMP in the outer segment. The free cGMP cannot be measured directly 

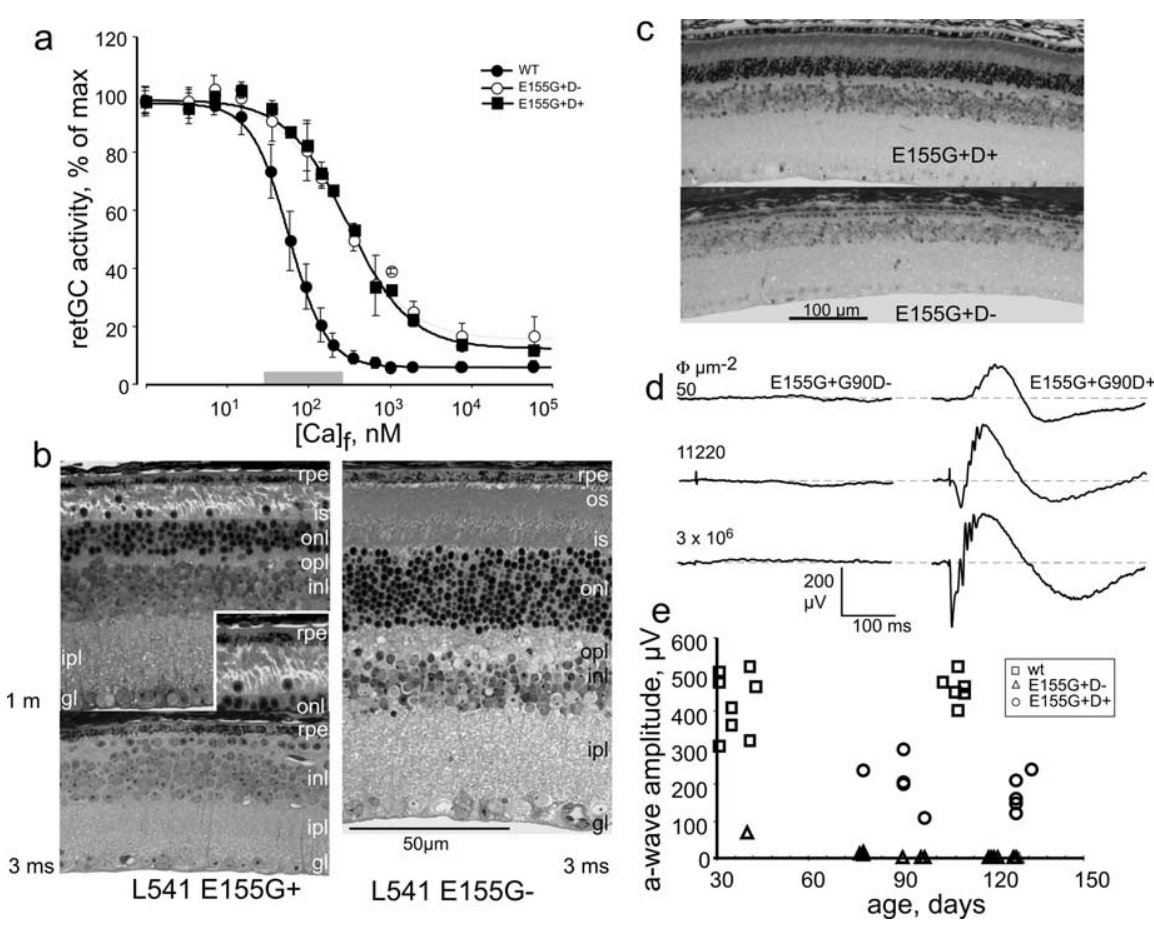

Figure 7. Retinal degeneration in mice expressing E155G GCAP-1 and its rescue by G90D rhodopsin. $\boldsymbol{a}$, Shift in $\mathrm{Ca}^{2+}$ sensitivity of retGC in 3.5-week-old mice expressing E155G GCAP-1 in E155G (white circles; $n=2$ ) or E155G/G90D littermates (black squares; $n=3$ ) compared with WT (black circles; $n=5$ ). For additional detail, see Figure $1 . \boldsymbol{b}$, Retinal degeneration in $L 541$ line expressing E155G GCAP- 1 in $R^{+/+}$background at 1 month and 3 months of age (left); a nonexpressing WT littermate of E155G L541 mice at 3 months of age is shown on the right ( $40 \times$ objective). The inset in left top panel shows distal portion of the retina in more detail. Notice the drastically distorted and dispersed outer segments at 1 month of age. rpe, Retinal pigment epithelium; is, inner segments; os, outer segments; onl, outer nuclear layer; opl, outer plexiform layer; inl, inner nuclear layer; ipl, inner plexiform layer; gl, ganglion cell layer. c, Rescue of rods in E155G/G90D (top) mouse compared with its E155G littermate (bottom) at 4 months of age (20× objective). $\boldsymbol{d}$, Restoration in E155G/G90D mice of ERG responses lacking in their E155G littermates. e, Maximal ERG a-wave amplitude in WT (squares), E155G (triangles), and their E155G/G90D littermates (circles). Each data point represents a separate mouse.

with biochemical or immunocytochemical methods (Kilbride and Ebrey, 1979; Govardovskii and Berman, 1981) because $>95 \%$ of total cGMP in the photoreceptors is tightly bound (Gillespie and Beavo, 1989), with only a small fraction regulating the cGMP-gated channels in light and darkness (Yau and Baylor, 1989). Because, however, the ratios of the maximum value of the current densities from the various animals were very close to the ratios of our estimates of outer segment free-Ca ${ }^{2+}$ (Matthews and Fain, 2003), it is likely that changes in both current density and $\mathrm{Ca}^{2+}$ reflect changes in the free concentration of cGMP in the outer segment. Our results would then show that the Y99C mutation of GCAP-1 increases free cGMP as the result of an alteration of $\mathrm{Ca}^{2+}$-binding in EF-hand domain 3 of the protein (Dizhoor et al., 1998, 2006; Sokal et al., 1998, 2005; Wilkie et al., 2001) and that the rhodopsin G90D mutation effectively reduces this abnormally elevated cGMP level by constitutive activation of the transduction cascade.

Elevated $\mathrm{Ca}^{2+}$ in photoreceptors is thought to be an important apoptotic trigger for retinal degeneration (He et al., 2000). In the animals we examined, degeneration is correlated with the increased circulating current density that produces an increase in intracellular $\mathrm{Ca}^{2+}$ (Olshevskaya et al., 2004, Makino et al., 2006) (Fig. $4 b$, Table 1). None of our experiments excludes the possibility, however, that the increased level of cGMP either by itself or in combination with elevated $\mathrm{Ca}^{2+}$ can contribute to the onset and progression of photoreceptor degeneration. Although we measured $\mathrm{Ca}^{2+}$ in the outer segment, apoptosis is more likely to be triggered in the inner segment by diffusion for example into the adjacent mitochondria of the ellipsoid. The direct measurement of changes in free $\mathrm{Ca}^{2+}$ in mouse rod inner segments with fluorescent indicator dyes is not yet possible and presents many difficulties, including the small volume of inner segment cytoplasm and the high basal level of $\mathrm{Ca}^{2+}$, for example in the mitochondria. There are in addition no biochemical methods presently available to make direct measurements of free cGMP. Measurements of total cGMP cannot distinguish changes in the much smaller fraction of the free cGMP in the outer segment (Kilbride and Ebrey, 1979), much less in the inner segment. Although our experiments are consistent with the notion that the degeneration in Y99C mice is produced by elevated $\mathrm{Ca}^{2+}$, definitive proof of this hypothesis must await methods for increasing outer (and inner) segment $\mathrm{Ca}^{2+}$ without accompanying changes in free cGMP.

Activation of the PDE6 by G90D, which decreases the probability of channel opening and reduces $\mathrm{Ca}^{2+}$ influx, preserves $>50 \%$ of photoreceptors at a time when both Y99C and E155G GCAP-1 siblings lacking the G90D transgene lose the entire outer nuclear layer (Figs. 5, 7). This effect is even more dramatic in E155G mice. In the absence of G90D transgene, the E155G rods are severely compromised as early as 3-4 weeks of age to such an extent that their abnormally short outer segments are not even suitable for single-cell recording (Fig. 7), hence the lack of single-cell data for E155G mice in this study. However, the presence of the G90D transgene drastically increases the rate of survival of the photoreceptors even in this model of severe retinal degeneration (Fig. 7).

In addition to their nearly normal morphological appearance (Figs. 5, 7), the surviving rods in both G90D/Y99C and G90D/ E155G mice also remain functional. Despite the reduction by almost an order of magnitude in the light sensitivity of the rescued rods, the ERG responses were robust at the time when the nonrescued siblings had, at best, only rudimentary ERG responses or none at all (Figs. 6, 7). We did not observe 100\% rescue, probably because expression of both Y99C GCAP-1 and G90D rhodopsin among the photoreceptors was non-uniform, and G90D expression may have been less effective in preserving the viability of those rods that produce higher levels of the mutant GCAP-1 (and/or lower levels of the G90D rhodopsin).

Prolonged exposure of the Y99C mice to 200-700 lux ambient light also partially rescued photoreceptors (Fig. 8). The preservation was much less than in Y99C/G90D animals, in which the cascade was continuously activated, probably reflecting the difficulty of maintaining a truly constant light stimulation of the photoreceptors. The light intensity at the retina must have been quite different during periods of inactivity, when the mice huddled together with closed eyelids, and during periods of activity, when they had their eyes open. In a different strain of mice (L52) that expresses lower levels of Y99C GCAP-1 (Olshevskaya et al., 
2004), preliminary results of another group also indicate that prolonged ambient light exposure can be effective in preserving retinal morphology and function (Dr. Tiansen Li, personal communication). However, it also needs to be noted that prolonged exposure to constant bright light can significantly reduce ERG amplitudes in normal pigmented mice (Lyubarsky et al., 2004).

Previous observations have pointed to a decrease in the $\mathrm{Ca}^{2+}$ sensitivity of cGMP synthesis as a possible explanation for the onset of apoptosis in photoreceptors harboring specific mutations in retGC1 and GCAP-1 (for review, see Bird et al., 2002; Olshevskaya et al., 2002; Dizhoor et al., 2006). In human patients, these mutations usually first appear as cone and cone-rod degenerations in the macula (Payne et al., 1998; Wilkie et al., 2001, Sokal et al., 2005). In mice, which do not have a macula, the mutant GCAP-1 is expressed primarily under a rod-specific promoter that is also somewhat active in the cones (Woodford et al., 1994). Despite these differences, mouse rods progressively degenerate specifically in response to mutant GCAP-1 expression and can therefore be considered an appropriate model for evaluating the mechanism of human photoreceptor death triggered by GCAP-1 mutations. Our experiments show that progressive severe photoreceptor loss occurs in GCAP-1 Y99C mice (Fig. 5), with an ERG barely, if at all, detectable by $3-4$ months of age (Figs. $6 a, b, 7 b, d$ ), Furthermore, the degeneration is caused by elevation of cGMP and $\mathrm{Ca}^{2+}$ through the abnormal activity of retGC in the darkness, which can be mitigated by stimulation of cGMP hydrolysis by PDE6. Thus, constitutive activation of the phototransduction cascade by G90D rhodopsin, which by itself produces human stationary night blindness (Sieving et al., 1995), is nevertheless capable of rescuing photoreceptors from death in exchange for lower light sensitivity. Because low light sensitivity is preferable to none at all, it may be useful to explore G90D rhodopsin expression as a possible genetic approach to the treatment of congenital blindness produced by elevated cGMP production in certain inherited retinal disorders.

\section{References}

Baylor DA, Lamb TD, Yau KW (1979) The membrane current of single rod outer segments. J Physiol (Lond) 288:589-611.

Brooks SP, Storey KB (1992) Bound and determined: a computer program for making buffers of defined ion concentrations. Anal Biochem 201:119-126.

Burns ME, Arshavsky VY (2005) Beyond counting photons: trials and trends in vertebrate visual transduction. Neuron 48:387-401.

Burns ME, Mendez A, Chen J, Baylor DA (2002) Dynamics of cyclic GMP synthesis in retinal rods. Neuron 36:81-91.

Calvert PD, Govardovskii VI, Krasnoperova N, Anderson RE, Lem J, Makino CL (2001) Membrane protein diffusion sets the speed of rod phototransduction. Nature 411:90-94.

Dizhoor AM, Boikov SG, Olshevskaya EV (1998) Constitutive activation of photoreceptor guanylate cyclase by Y99C mutant of GCAP-1. Possible role in causing human autosomal dominant cone degeneration. J Biol Chem 273:17311-17314.

Dizhoor AM, Olshevskaya EV, Peshenko IV (2006) $\mathrm{Ca}^{2+}$-sensitivity of photoreceptor guanylyl cyclase (retGC) and congenital photoreceptor degeneration: modeling in vitro and in vivo. In: Neuronal calcium sensor proteins (Philippov PP, Koch K-W, eds), pp 203-219. New York: Nova.

Fain GL, Matthews HR, Cornwall MC, Koutalos Y (2001) Adaptation in vertebrate photoreceptors. Physiol Rev 81:117-151.

Fan J, Woodruff ML, Cilluffo MC, Crouch RK, Fain GL (2005) Opsin activation of transduction in the rods of dark-reared Rpe65 knockout mice. J Physiol (Lond) 568:83-95.

Field GD, Rieke F (2002) Nonlinear signal transfer from mouse rods to bipolar cells and implications for visual sensitivity. Neuron 34:773-785.

Gillespie PG, Beavo JA (1989) cGMP is tightly bound to bovine retinal rod phosphodiesterase. Proc Natl Acad Sci USA 86:4311-4315.

Govardovskii VI, Berman AL (1981) Light-induced changes of cyclic GMP content in frog retinal outer segments measured with rapid freezing and microdissection. Biophys Struct Mech 7:125-130.

He L, Poblenz AT, Medrano CJ, Fox DA (2000) Lead and calcium produce rod photoreceptor cell apoptosis by opening the mitochondrial permeability transition pore. J Biol Chem 275:12175-12184.

Hodgkin AL, McNaughton PA, Nunn BJ (1987) Measurement of sodiumcalcium exchange in salamander rods. J Physiol (Lond) 391:347-370. 
Humphries MM, Rancourt D, Farrar GJ, Kenna P, Hazel M, Bush RA, Sieving PA, Sheils DM, McNally N, Creighton P, Erven A, Boros A, Gulya K, Capecchi MR, Humphries P (1997) Retinopathy induced in mice by targeted disruption of the rhodopsin gene. Nat Genet 15:216-219.

Hurley JB, Dizhoor AM (2000) Heterologous expression and assays for photoreceptor guanylyl cyclases and guanylyl cyclase activating proteins. Methods Enzymol 315:708-717.

Jin S, Cornwall MC, Oprian DD (2003) Opsin activation as a cause of congenital night blindness. Nat Neurosci 6:731-735.

Kelsell RE, Gregory-Evans K, Payne AM, Perrault I, Kaplan J, Yang RB, Garbers DL, Bird AC, Moore AT, Hunt DM (1998) Mutations in the retinal guanylate cyclase (RETGC-1) gene in dominant cone-rod dystrophy. Hum Mol Genet 7:1179-1184.

Kilbride P, Ebrey TG (1979) Light-initiated changes of cyclic guanosine monophosphate levels in the frog retina measured with quick-freezing techniques. J Gen Physiol 74:415-426.

Koch KW, Stryer L (1988) Highly cooperative feedback control of retinal rod guanylate cyclase by calcium ions. Nature 334:64-66.

Koutalos Y, Nakatani K, Tamura T, Yau KW (1995) Characterization of guanylate cyclase activity in single retinal rod outer segments. J Gen Physiol 106:863-890.

Lyubarsky AL, Lem J, Chen J, Falsini B, Iannaccone A, Pugh Jr EN (2002) Functionally rodless mice: transgenic models for the investigation of cone function in retinal disease and therapy. Vision Res 42:401-415.

Lyubarsky AL, Daniele LL, Pugh Jr EN (2004) From candelas to photoisomerizations in the mouse eye by rhodopsin bleaching in situ and the light-rearing dependence of the major components of the mouse ERG. Vision Res 44:3235-3251.

Makino CL, Dodd RL, Chen J, Burns ME, Roca A, Simon MI, Baylor DA (2004) Recoverin regulates light-dependent phosphodiesterase activity in retinal rods. J Gen Physiol 123:729-741.

Makino CL, Wen XH, Michaud N, Peshenko IV, Pawlyk B, Brush RS, Soloviev M, Liu X, Woodruff ML, Calvert PD, Savchenko AB, Anderson RE, Fain GL, Li T, Sandberg MA, Dizhoor AM (2006) Effects of low AIPL1 expression on phototransduction in rods. Invest Ophthalmol Vis Sci 47:2185-2194.

Marks PW, Maxfield FR (1991) Preparation of solutions with free calcium concentration in the nanomolar range using 1,2-bis(o-aminophenoxy)ethane$\mathrm{N}, \mathrm{N}, \mathrm{N}^{\prime}, \mathrm{N}^{\prime}$-tetraacetic acid. Anal Biochem 193:61-71.

Matthews HR, Fain GL (2003) The effect of light on outer segment calcium in salamander rods. J Physiol (Lond) 552:763-776.

Mendez A, Burns ME, Sokal I, Dizhoor AM, Baehr W, Palczewski K, Baylor DA, Chen J (2001) Role of guanylate cyclase-activating proteins (GCAPs) in setting the flash sensitivity of rod photoreceptors. Proc Natl Acad Sci USA 98:9948-9953.

Newbold RJ, Deery EC, Payne AM, Wilkie SE, Hunt DM, Warren MJ (2002) Guanylate cyclase activating proteins, guanylate cyclase and disease. Adv Exp Med Biol 514:411-438.

Nishiguchi KM, Sokal I, Yang L, Roychowdhury N, Palczewski K, Berson EL, Dryja TP, Baehr W (2004) A novel mutation (I143NT) in guanylate cyclase-activating protein 1 (GCAP1) associated with autosomal dominant cone degeneration. Invest Ophthalmol Vis Sci 45:3863-3870.

Olshevskaya EV, Hughes RE, Hurley JB, Dizhoor AM (1997) Calcium binding, but not a calcium-myristoyl switch, controls the ability of guanylyl cyclase-activating protein GCAP-2 to regulate photoreceptor guanylyl cyclase. J Biol Chem 272:14327-14333.

Olshevskaya EV, Ermilov AN, Dizhoor AM (2002) Factors that affect regulation of cGMP synthesis in vertebrate photoreceptors and their genetic link to human retinal degeneration. Mol Cell Biochem 230:139-147.

Olshevskaya EV, Calvert PD, Woodruff ML, Peshenko IV, Savchenko AB, Makino CL, Ho YS, Fain GL, Dizhoor AM (2004) The Y99C mutation in guanylyl cyclase-activating protein 1 increases intracellular $\mathrm{Ca}^{2+}$ and causes photoreceptor degeneration in transgenic mice. J Neurosci 24:6078-6085.

Palczewski K, Polans AS, Baehr W, Ames JB (2000) $\mathrm{Ca}^{2+}{ }^{2+}$ binding proteins in the retina: structure, function, and the etiology of human visual diseases. BioEssays 22:337-350.

Payne AM, Downes SM, Bessant DA, Taylor R, Holder GE, Warren MJ, Bird AC, Bhattacharya SS (1998) A mutation in guanylate cyclase activator 1A (GUCA1A) in an autosomal dominant cone dystrophy pedigree mapping to a new locus on chromosome 6p21.1. Hum Mol Genet 7:273-277.

Peshenko IV, Dizhoor AM (2004) Guanylyl cyclase-activating proteins (GCAPs) are $\mathrm{Ca}^{2+} / \mathrm{Mg}^{2+}$ sensors: implications for photoreceptor guany- lyl cyclase (RetGC) regulation in mammalian photoreceptors. J Biol Chem 279:16903-16906.

Peshenko IV, Dizhoor AM (2006) $\mathrm{Ca}^{2+}$ and $\mathrm{Mg}^{2+}$ binding properties of GCAP-1. Evidence that $\mathrm{Mg}^{2+}$-bound form is the physiological activator of photoreceptor guanylyl cyclase. J Biol Chem 281:23830-23841.

Peshenko IV, Moiseyev GP, Olshevskaya EV, Dizhoor AM (2004) Factors that determine $\mathrm{Ca}^{2+}$ sensitivity of photoreceptor guanylyl cyclase. Kinetic analysis of the interaction between the $\mathrm{Ca}^{2+}$-bound and the $\mathrm{Ca}^{2+}$ free guanylyl cyclase activating proteins (GCAPs) and recombinant photoreceptor guanylyl cyclase 1 (RetGC-1). Biochemistry 43:13796-13804.

Pugh Jr EN, Lamb TD (1993) Amplification and kinetics of the activation steps in phototransduction. Biochim Biophys Acta 1141:111-149.

Pugh Jr EN, Duda T, Sitaramayya A, Sharma RK (1997) Photoreceptor guanylate cyclases: a review. Biosci Rep 17:429-473.

Ramamurthy V, Tucker C, Wilkie SE, Daggett V, Hunt DM, Hurley JB (2001) Interactions within the coiled-coil domain of RetGC-1 guanylyl cyclase are optimized for regulation rather than for high affinity. J Biol Chem 276:26218-26229.

Rao VR, Cohen GB, Oprian DD (1994) Rhodopsin mutation G90D and a molecular mechanism for congenital night blindness. Nature 367:639-642.

Sato M, Nakazawa M, Usui T, Tanimoto N, Abe H, Ohguro H (2005) Mutations in the gene coding for guanylate cyclase-activating protein 2 (GUCA1B gene) in patients with autosomal dominant retinal dystrophies. Graefes Arch Clin Exp Ophthalmol 243:235-242.

Sieving PA, Richards JE, Naarendorp F, Bingham EL, Scott K, Alpern M (1995) Dark-light: model for nightblindness from the human rhodopsin Gly-90 $\rightarrow$ Asp mutation. Proc Natl Acad Sci USA 92:880-884.

Sieving PA, Fowler ML, Bush RA, Machida S, Calvert PD, Green DG, Makino CL, McHenry CL (2001) Constitutive "light" adaptation in rods from G90D rhodopsin: a mechanism for human congenital nightblindness without rod cell loss. J Neurosci 21:5449-5460.

Sokal I, Li N, Surgucheva I, Warren MJ, Payne AM, Bhattacharya SS, Baehr W, Palczewski K (1998) GCAP1 (Y99C) mutant is constitutively active in autosomal dominant cone dystrophy. Mol Cell 2:129-133.

Sokal I, Dupps WJ, Grassi MA, Brown Jr J, Affatigato LM, Roychowdhury N, Yang L, Filipek S, Palczewski K, Stone EM, Baehr W (2005) A novel GCAP1 missense mutation (L151F) in a large family with autosomal dominant conerod dystrophy (adCORD). Invest Ophthalmol Vis Sci 46:1124-1132.

Tsang SH, Woodruff ML, Chen CK, Yamashita CY, Cilluffo MC, Rao AL, Farber DB, Fain GL (2006) GAP-Independent termination of photoreceptor light response by excess gamma subunit of the c-GMPphosphodiesterase. J Neurosci 26:4472-4480.

Tsien R, Pozzan T (1989) Measurement of cytosolic free $\mathrm{Ca}^{2+}$ with quin2. Methods Enzymol 172:230-262.

Tucker CL, Woodcock SC, Kelsell RE, Ramamurthy V, Hunt DM, Hurley JB (1999) Biochemical analysis of a dimerization domain mutation in RetGC-1 associated with dominant cone-rod dystrophy. Proc Natl Acad Sci USA 96:9039-9044.

Wilkie SE, Newbold RJ, Deery E, Walker CE, Stinton I, Ramamurthy V, Hurley JB, Bhattacharya SS, Warren MJ, Hunt DM (2000) Functional characterization of missense mutations at codon 838 in retinal guanylate cyclase correlates with disease severity in patients with autosomal dominant cone-rod dystrophy. Hum Mol Genet 9:3065-3073.

Wilkie SE, Li Y, Deery EC, Newbold RJ, Garibaldi D, Bateman JB, Zhang H, Lin W, Zack DJ, Bhattacharya SS, Warren MJ, Hunt DM, Zhang K (2001) Identification and functional consequences of a new mutation (E155G) in the gene for GCAP1 that causes autosomal dominant cone dystrophy. Am J Hum Genet 69:471-480.

Woodford BJ, Chen J, Simon MI (1994) Expression of rhodopsin promoter transgene product in both rods and cones. Exp Eye Res 58:631-635.

Woodruff ML, Sampath AP, Matthews HR, Krasnoperova NV, Lem J, Fain GL (2002) Measurement of cytoplasmic calcium concentration in the rods of wild- type and transducin knock-out mice. J Physiol (Lond) 542:843-854.

Woodruff ML, Wang Z, Chung HY, Redmond TM, Fain GL, Lem J (2003) Spontaneous activity of opsin apoprotein is a cause of Leber congenital amaurosis. Nat Genet 35:158-164.

Yau KW, Baylor DA (1989) Cyclic GMP-activated conductance of retinal photoreceptor cells. Annu Rev Neurosci 12:289-327.

Yau KW, Nakatani K (1984) Electrogenic Na-Ca exchange in retinal rod outer segment. Nature 311:661-663. 